\title{
PET CARE KALIMANTAN BARAT DI KOTA PONTIANAK
}

\author{
Busainah Nuurkholillah ${ }^{1}$, Syaiful Muazir ${ }^{2}$, Hamdil Khaliesh ${ }^{3}$ \\ ${ }^{1}$ Mahasiswa, Program Studi Arsitektur, Fakultas Teknik, Universitas Tanjungpura. \\ busainahn@gmail.com \\ ${ }^{2}$ Program Studi Arsitektur, Fakultas Teknik, Universitas Tanjungpura \\ ${ }^{3}$ Program Studi Arsitektur, Fakultas Teknik, Universitas Tanjungpura
}

Naskah diajukan pada: 1 Februari 2021

Naskah revisi akhir diterima pada: 3 Februari 2021

\begin{abstract}
Abstrak
Hewan memang tidak bisa terlepas dari kehidupan sehari - hari manusia dikarenakan kehidupan seimbang antara manusia, hewan, dan lingkungan sekitar. Hewan peliharaan adalah hewan jinak, sebagai contoh kucing atau anjing, dipelihara sebagai teman, diperlakukan dengan cinta dan kasih sayang. Sebagian dari hewan tersebut dipelihara karena memiliki karakteristik ataupun karena keindahannya. Adanya penjabaran berupa data penyakit hewan dan kesehatan hewan yang menjadi utama pembahasan pet care. Di Kota Pontianak terdapat banyak pet shop ataupun klinik dengan dokter hewan sebagai penanggung jawab nya. Letak pet shop dan klinik tersebut tersebar dan juga ada yang bergabung atau bersebelahan dengan ruko atau area komersil umum lain. Untuk kegiatan atau event juga biasa diadakan di tempat umum dan bebas tidak pada satu tempat tetap. Metode perancangan adalah untuk mengetahui sesuatu melalui tahapan yang sistematis. Metode perancangan yang digunakan adalah menurut J. C. Jones dalam buku Metode Perancangan Arsitektur. Tahap yang digunakan ialah tahp gagasan, informasi, analisis, sintesis, evaluasi, dan optimisasi. Tujuan yang ingin dicapai ialah untuk merumuskan perencanaan dan perancangan Pet Care Kalimantan Barat di Kota Pontianak yang dapat memfasilitasi sarana kesehatan, perawatan, penitipan, dan kegiatan yang berkaitan dengan hewan, dan café serta retail shop untuk pengunjung umum.
\end{abstract}

Kata-kata Kunci: hewan, perawatan

\begin{abstract}
Animals are inseparable from human daily life because life is balanced between humans, animals and the surrounding environment. Pets are domestic animals, for example cats or dogs, kept as friends, treated with love and affection. Some of these animals are kept because of their characteristics or because of their beauty. There is a description in the form of data on animal diseases and animal health which is the main discussion of pet care. In Pontianak City, there are many pet shops or clinics with veterinarians in charge. The location of the pet shops and clinics are scattered and some are joined to or adjacent to shop houses or other public commercial areas. Activities or events are also usually held in public places and are free, not in one fixed place. The design method is to find out something through systematic stages. The design method used is according to J. C. Jones in the book Architectural Design Methods. The stages used are the stages of ideas, information, analysis, synthesis, evaluation, and optimization. The goal to be achieved is to formulate the planning and design of West Kalimantan Pet Care in Pontianak City that can facilitate health facilities, care, care, and activities related to animals, and cafes and retail shops for general visitors.
\end{abstract}




\section{Pendahuluan}

Hewan memang tidak bisa terlepas dari kehidupan sehari-hari manusia dikarenakan kehidupan seimbang antara manusia, hewan, dan lingkungan sekitar. Menurut UU No. 18 Tahun 2009 Tentang Peternakan dan Kesehatan Hewan, tepatnya pada Pasal 1 menyebutkan bahwa hewan adalah binatang atau satwa yang seluruh atau sebagian dari siklus hidupnya berada di darat, air, dan/atau udara, baik yang dipelihara maupun yang di habitatnya. Hewan peliharaan adalah hewan jinak yang biasa dipelihara, sebagai contoh kucing, anjing, hewan kecil seperti hamster ataupun kelinci, dipelihara sebagai teman diperlakukan dengan cinta dan kasih sayang. Hewan kesayangan atau hewan pendamping merupakan hewan yang dipelihara oleh manusia untuk dijadikan sebagai teman atau kesenangan. Sebagian dari hewan tersebut dipelihara karena memiliki karakteristik ataupun karena keindahannya.

Capaian Kinerja Terkendalinya Penyakit Hewan Menular Strategis yaitu Pengendalian penyakit Hewan Menular Strategis di Kalimantan Barat pada tahun 2018 dapat digambarkan dengan lima jenis penyakit hewan yang banyak ditemukan di Provinsi Kalimantan Barat yaitu Rabies, Flu Burung, Brucellosis, Hog Cholera, dan Japanese Encephalitis. Untuk rabies menjadi penyakit hewan yang sering ditemukan karena penyakit rabies merupakan salah satu jenis penyakit zoonosis atau menular yang menyerang susunan syaraf pusat dan rabies dengan kasus sebanyak 546 buah pada manusia berdasarkan jenis kelamin dan usia penderita. Rabies masih dianggap penyakit penting di Indonesia karena bersifat fatal dan dapat menimbulkan kematian. Biasanya rabies ditemukan pada hewan yang biasa dipelihara oleh manusia seperti anjing ataupun kucing. (Dinas Pangan, Peternakan, dan Kesehatan Hewan Kalimantan Barat, 2017).

Di Kota Pontianak terdapat banyak pet shop ataupun klinik dengan dokter hewan sebagai penanggung jawab nya. Letak pet shop dan klinik tersebut tersebar dan juga ada yang bergabung atau bersebelahan dengan ruko atau area komersil umum lain. Untuk kegiatan atau event juga biasa diadakan di tempat umum dan bebas tidak pada satu tempat tetap.

Dari penjelasan uraian diatas dapat diambil kesimpulan bahwa dibutuhkan nya suatu tempat tetap untuk bisa menampung segala aktifitas dan fasilitas lengkap untuk hewan khususnya hewan peliharaan dengan fasilitas utama yaitu untuk kepentingan kesehatan hewan. Semua berdasarkan untuk membantu melayani kesehatan hewan berdasarkan data angka penyakit hewan pada anjing maupun kucing dan small pet atau hewan kesayangan lain berupa hamster dan kelinci. Dengan melihat kondisi keberlangsungan tempat pelayanan kesehatan dan perawatan hewan yang perbulan nya mendata hanya dua jenis hewan yang sangat sering mengalami kasus penyakit. Kemudian ide menggabungkan fasilitas dan tempat khusus hewan dan manusia di satu tempat berdasarkan wawancara dengan pemilik hewan. Serta melihat dari studi kasus pada bangunan khusus hewan yang sudah ada.

\section{Kajian Pustaka}

Pet berarti membelai, menimang, kesayangan, dan binatang kesayangan. Sedangkan care adalah perawatan, perhatian, perlindungan, dan pemeliharaan. Jadi pet care sendiri artinya adalah sarana yang memiliki fasilitas pelayanan perawatan dan pemeliharaan, pada hewan khususnya hewan kesayangan. Tidak hanya berfokuskan pada kesehatan, tapi juga mempertimbangkan hal perawatan itu sendiri seperti penitipan hewan, rekreasi, pusat informasi, penyedia kebutuhan hewan, dan bisa menjadi tempat interaksi bagi pecinta hewan (Amie, 2007).

Usaha di bidang kesehatan hewan adalah kegiatan yang menghasilkan produk dan jasa yang menunjang upaya dalam mewujudkan kesehatan hewan. Pelayanan pada pet care berupa klinik hewan. Pada Peraturan Menteri Pertanian tahun 2010 tentang Pedoman Pelayanan Jasa Medik Veteriner menjelaskan, klinik hewan adalah tempat usaha pelayanan jasa medik veteriner yang dijalankan oleh suatu manajemen dengan dipimpin oleh seorang dokter hewan penanggung jawab dan memiliki fasilitas untuk pengamatan hewan yang mendapat gangguan kesehatan tertentu. 
Hewan kesayangan berbeda dari hewan ternak, hewan percobaan, hewan pekerja, atau hewan tunggangan yang dipelihara untuk kepentingan ekonomi atau untuk melakukan tugas tertentu. Dalam lingkup pet care ini, jenis hewan kesayangan yaitu anjing, kucing, small pet. (Our World Encyclopedia, 1974).

Fasilitas pendukung pada Pet Care berdasarkan fungsi dari Pet Care itu sendiri dapat berupa tempat pelayanan pengunjung umum, hewan, dan sebagai sarana edukasi dan rekreasi. Tempat pelayanan pengunjung umum merupakan tempat kegiatan perdagangan yang bersifat komersial, dimana terjadi pertukaran uang, barang, dan jasa antara penjual dan pembeli. Fasilitas yang mencakup tempat fasilitas pendukung untuk pengunjung umum terdiri dari Retail Shop dan Café and culinary. Untuk tempat pelayanan jasa hewan merupakan tempat kegiatan penjualan dan jasa khusus hewan. Fasilitas ini berupa klinik hewan yang berfungsi mengobati hewan peliharaan yang sakit baik memerlukan karantina maupun tidak dengan didukung fasilitas berupa grooming dan hotel pet diperuntukkan khusus penginapan hewan peliharaan yang dititipkan oleh pemiliknya. Terdiri dari klinik hewan, Pet Shop, Pet Grooming, Pet Hotel, Pet Show / Expo. Selanjutnya sebagai sarana edukasi dan rekreasi yang menjadi tempat edukasi bagi hewan karena memberi pelayanan training pada hewan khususnya anjing karena dapat dilatih untuk keamanan maupun kebutuhan lain.

Menurut Peraturan Menteri Pertanian tahun 2010 tentang Pedoman Pelayanan Jasa Medik Veteriner berikut adalah persyaratan umum yang harus dimiliki oleh klinik hewan, seperti memiliki surat perizinan sebagaimana yang sudah ditetapkan, dan memiliki tempat yang sekurang - kurangnya harus dilengkapi dengan tempat untuk menunggu klien dan pasien yang memadai. Tersedia ruang kerja untuk meletakkan meja periksa, uji sederhana, peralatan medik veteriner, lemari obat, peralatan untuk administrasi dan rekam medik. Sistem penerangan dan sirkulasi udara yang memadai. Sumber air bersih, sistem drainase, sistem penanganan limbah, sistem kemanan untuk menjamin kesehatan manusia, hewan, lingkungan dan sistem komunikasi.

Untuk Pet Care sendiri berdasarkan UU No. 18 tahun 2009 menyesuaikan konsep dan fungsi berupa pemeliharaan dan perawatan serta serta perlakuan dan pengayoman yang wajar terhadap hewan. Jenis tindakan tersebut sesuai konsep training yang merupakan perlakuan hewan yang berguna untuk melatih hewan. Selain itu memiliki tindakan perawatan berupa fungsi kesehatan hewan, perawatan, maupun komersil, yang berada di lingkup Pet Care.

Fasilitas lain yang ada pada Pet Care ini yaitu pet training atau pelatihan yang digunakan yaitu Agility Training. Merupakan pelatihan ketangkasan yang melatih khusus hewan anjing dengan menggunakan berbagai macam rintangan di lapangan seluas maksimal $900 \mathrm{~m} 2$. Pada pelatihan ini, anjing dilatih untuk ketangkasan dengan tujuan baik untuk keperluan keamanan maupun sehari - hari dan olahraga. Agility Training pada Pet Care ini bukan untuk dikhususkan pada adu bakat atau penampilan di suatu kontes (Pet Show), melainkan fokus pada ketangkasan anjing yang memiliki tujuan tertentu. Pengamanan lapangan training berupa dinding dengan ketinggian minimum $170 \mathrm{~cm}$ dan kawat $80 \mathrm{~cm}$ (Federation Cynologique Internationale, 2018).

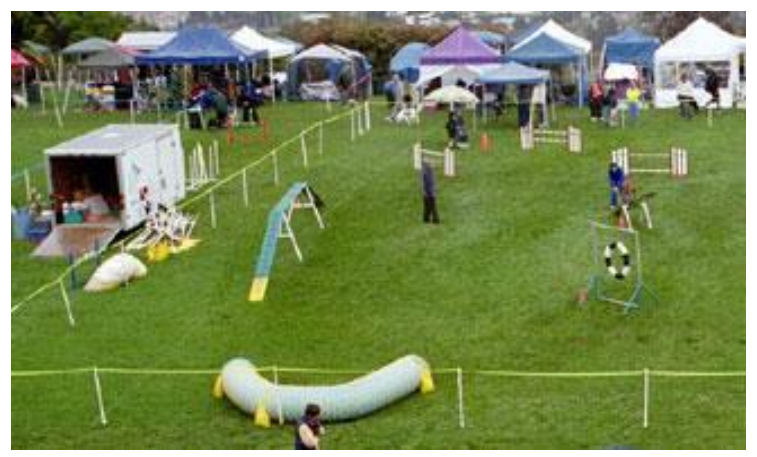

Gambar 1. Agility Training Area

Sumber: Federation Cynologique Internationale, 2018 


\section{Metode}

Data di klasifikasi sebagai keterangan dan fakta pada suatu persoalan untuk dianalisis dan solusi. Data yang digunakan yaitu data primer dan sekunder. Data primer adalah data yang dikumpulkan langsung dari sumber utama. Cara mendapatkan data primer adalah survey dan wawancara atau observasi langsung oleh penulis mengenai kondisi tapak pada lokasi perancangan. Data sekunder adalah data tambahan untuk menunjang data primer dalam menyelesaikan perancangan. Data sekunder dapat berupa literatur atau dokumen, peraturan wilayah berkaitan serta standar - standar mengenai judul perancangan. Selain itu juga dilakukan studi kasus atau preseden.

Metode perancangan yang digunakan adalah menurut J. C. Jones dalam buku Metode Perancangan Arsitektur (Nuraini, 2010). Adapun 6 tahapan yang akan dilakukan yaitu, tahap gagasan, tahap informasi, tahap analisis, tahap sintesis, tahap evaluasi, dan tahap optimalisasi.

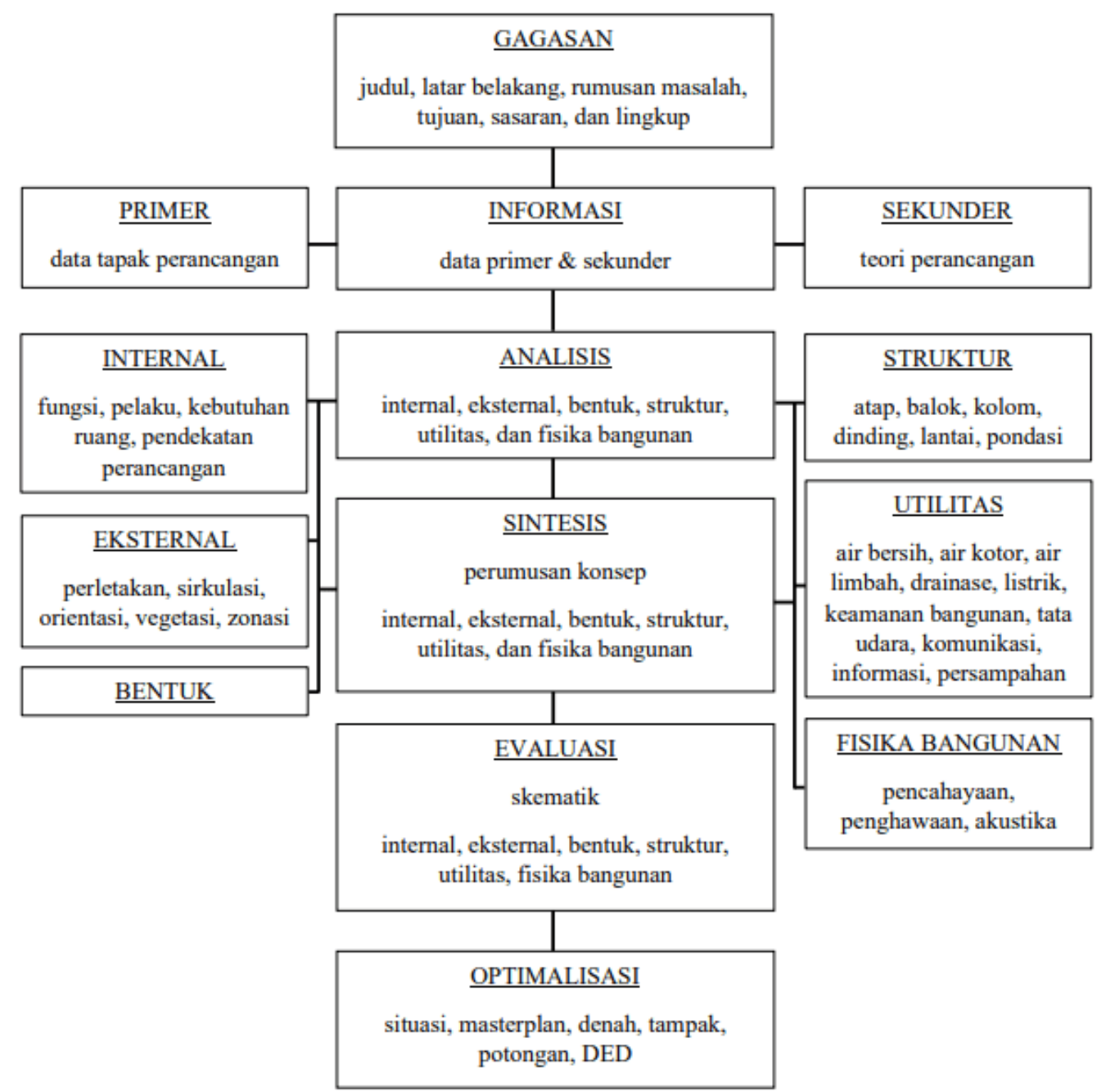

Gambar 2. Proses Perancangan

Sumber: Penulis, 2020

\section{Hasil dan Pembahasan}

\section{Landasan Konseptual}

\section{A. Internal}

Pet Care Kalimantan Barat di Kota Pontianak adalah suatu tempat khusus untuk hewan dengan berbagai pelayanan seperti jual beli aksesoris maupun perlengkapan lain untuk hewan (pet shop), pet 
grooming, pet training, klinik hewan, pet show / expo, serta café and culinary dan retail shop untuk fasilitas pengunjung. Tujuan Pet Care Kalimantan Barat di Kota Pontianak ini yaitu menjadikan suatu tempat khusus untuk hewan, selain itu juga baik untuk berkumpul, berinteraksi, antar pengunjung umum maupun pecinta hewan kesayangan. Fungsi Pet Care ini terbagi menjadi dua yaitu, fungsi utama pada Pet Care Kalimantan Barat yaitu sarana kesehatan hewan berupa pelayanan medis yang dapat melayanai kesehatan pengguna (pasien). Pelayanan medis yang dimaksud berbentuk klinik hewan yang terdiri dari Instalasi Gawat Darurat, Instalasi Rawat Jalan, Instalasi Rawat Inap, dan Farmasi (Apotek). Fungsi pendukung yang pertama yaitu perawatan hewan berupa pelayanan pet shop, pet grooming, pet hotel, pet training, dan pet show / expo. Fungsi kedua yaitu komersil untuk melayani pengunjung umum berupa café and culinary dan retail shop. Fungsi ketiga yaitu pengelola yang berupa kegiatan pengelolaan dan fungsi terakhir yaitu servis untuk tiap fungsi dan keberlangsungan pada Pet Care itu sendiri.

Pendekatan perancangan mengacu pada pemecahan permasalahan pada tapak atau site. Perencanaan pendekatan perancangan nantinya mempertimbangkan permasalahan lingkungan baik lokasi maupun keadaan sekitar. Permasalahan tapak yang akan dilakukan yaitu melibatkan analisis yang berisikan luasan site, kondisi wilayah, faktor manusia dan budaya, kondisi iklim, yang menghasilkan perletakan bangunan, orientasi, zonasi sekitar site maupun bangunan, keistimewaan alamiah berupa vegetasi yang digunakan, keistimewaan buatan sekitar, sirkulasi sekitar berupa arah masuk dan keluar, serta bagaimana kelancaran aksesibilitas baik dari site maupun dari luar.

\section{B. Eksternal}

Lokasi perancangan berada di Jl. Purnama, Kelurahan Akcaya, Kecamatan Pontianak Selatan, Kota Pontianak, Kalimantan Barat. Luas tapak \pm 7.000 m2 dengan KDB maksimal $80 \%$, KDB 60\%, KDH $40 \%$. GSB yaitu 6m, dan GSSB minimal $2 \mathrm{~m}$. Karakteristik lahan yaitu site berkontur datar, posisi site berada di pinggir jalan menjadi kemudahan pencapaian, berada dekat dengan fasilitas komersil dan umum, lokasi adalah lahan kosong dan sedikit lahan berada di pemukiman warga, dan pencapaian site memiliki satu jalan utama yaitu dari Jl. Purnama. Tapak dilakukan analisis dengan berdasarkan karakteristik tapak, kondisi lingkungan, manusia dan budaya, iklim, dll.

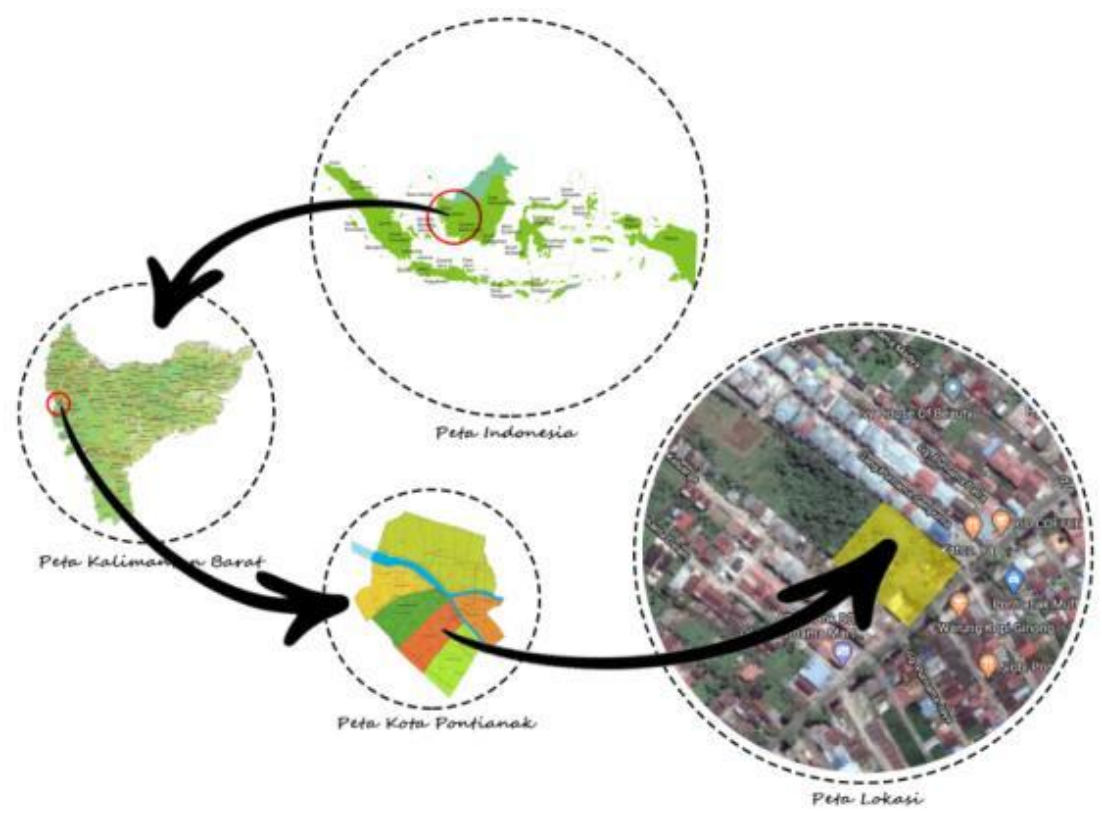

Gambar 3. Lokasi Perancangan

Sumber: Penulis, 2020 
Analisis perletakan pertimbangan didasari oleh peraturan pemerintah tentang fungsi lahan dan pengurangan luas lahan oleh GSB dan GSSB dan menghasilkan bangunan ke arah barat laut dan tenggara. Analisis orientasi yaitu orientasi bangunan mengikuti hadapan bangunan terhadap site. Orientasi dipengaruhi oleh view ke lingkungan sekitar, sinar matahari, dan orientasi bangunan itu sendiri. Analisis orientasi menghadap ke arah depan yaitu ke Jl. Purnama dan samping ke arah pemukiman warga. Pola sirkulasi sangat mempengaruhi keteraturan lalu lintas dan kenyamanan menuju site. Analisa sirkulasi dilakukan agar tidak ada kemacetan baik di dalam maupun di luar site dan juga agar pengunjung merasa nyaman dan aman. Analisis sirkulasi menghasilkan dua akses untuk masuk dan keluar dari Jl. Purnama. Analisis vegetasi dihasilkan dari qnalisa iklim, lingkungan sekitar, angin, cahaya matahari dan menghasilkan terdapat tiga jenis vegetasi yang dipakai yaitu vegetasi penghias memakai bunga asoka, vegetasi pengarah memakai pohon palem, dan vegetasi peneduh memakai pucuk merah. Analisis zoning menghasilkan zona publik di bagian selatan dan depan menyesuaikan orientasi bangunan fasad menghadap Jl. Purnama, semi publik di bagian tengah dan dekat dengan pemukiman warga, privat di bagian timur karena banyak terkena cahaya matahari pagi dan pertimbangan jauh dari kebisingan, semi privat di bagian depan dan timur karena banyak terkena cahaya matahari pagi dan pertimbangan jauh dari kebisingan, dan servis di area belakang site maupun bangunan dengan pertimbangan banyak terkena cahaya matahari sore.

\section{Konsep Perancangan}

\section{A. Konsep Bentuk}

Bentuk dasar bangunan yaitu persegi dan bangunan juga menyesuaikan zona ruang. Bangunan mengalami pengurangan bentuk pada belakang nangunan untuk fungsi sirkulasi bangunan. Kemudian bangunan mengalami penambahan bentuk pada sebelah kiri bangunan untuk menyesuaikan fungsi ruang.
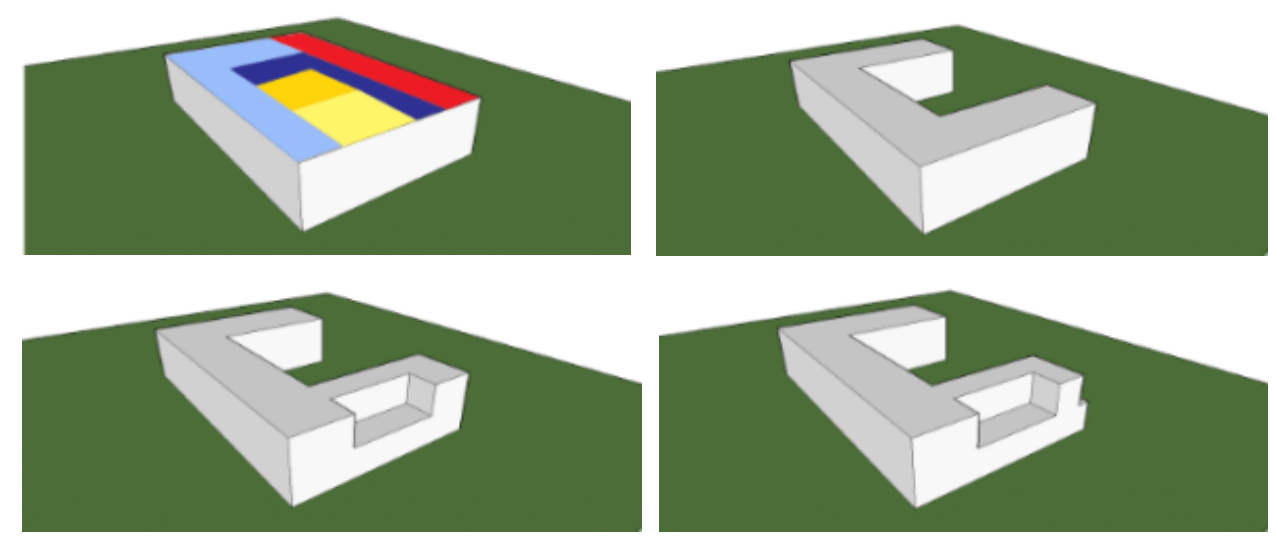

Gambar 4. Analisis Bentuk

Sumber: Penulis, 2020

Gubahan bentuk merupakan penyempurnaan dari hasil analisis bentuk yang menghasilkan bentukan dasar bangunan. Gubahan bentuk terdiri dari pengaplikasian atap bangunan, fasad, warna, maupun material yang digunakan pada eksterior bangunan. Terdapat atap perisai di beberapa area dan juga menggunakan atap Dak atau Datar. Kemudian terdapat secondary skin di beberapa fasad untuk mengurangi intensitas cahaya matahari yang masuk khususnya cahaya matahari sore. Finishing eksterior bangunan banyak dilapisi dengan material Aluminium Composite Panel (ACP) untuk menambah estetika. 


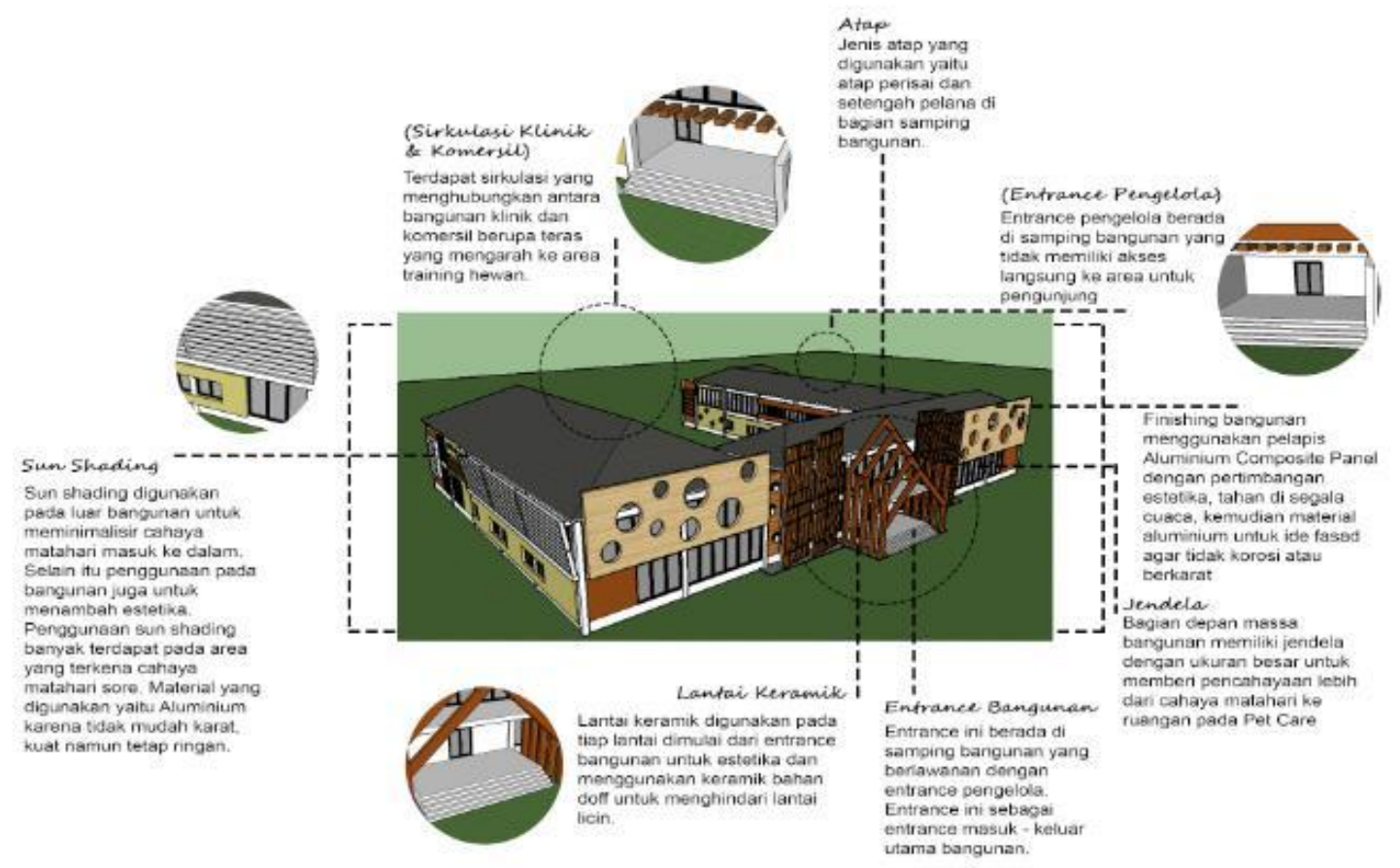

Gambar 5. Gubahan Bentuk

Sumber: Penulis, 2020

\section{B. Konsep Struktur}

Struktur atas bangunan ini menggunakan rangka atap baja ringan dan baja profil dengan pertimbangan lebih ringan, kuat, tidak karatan, serta bisa digunakan untuk bentang lebih dari $4 \mathrm{~m}$. Rangka atap yang digunakan yaitu rangka atap baja ringan dengan jenis atap yang digunakan yaitu atap perisai maupun pelana dengan pertimbangan atap miring cocok untuk iklim tropis. Untuk jenis struktur balok, kolom, pat lantai menggunakan beton dipertimbangkan dengan alasan kuat tekan beton bertulang relatif lebih tinggi dari bahan lain konstruksi lain, memiliki ketahanan yang tinggi terhadap api dan air. Sedangkan untuk dinding yang dipilih yaitu menggunakan material bata ringan dengan pertimbangan biaya, kemudahan pelaksanaan dan lebih rapi karena bentuk, ukuran, dan kualitas yang seragam. Dibanding dinding kayu yang tidak tahan air serta terbatasnya bentuk dan dinding batako yang lebih berat dan untuk desain bangunan tidak bisa berukuran besar. Selain itu beban ringan, kuat terhadap tegangan tinggi.

Struktur bawah dengan keadaan struktur tanah di Kota Pontianak termasuk ke dalam jenis tanah liat. Jenis tanah ini berupa gambut bekas endapan lumpur sungai Kapuas. Keadaan ini sangat labil dan mempunyai daya dukung yang rendah. Faktor pemilihan pondasi yaitu letak lokasi pembangunan, letak tanah keras di bawah permukaan, kondisi tanah bawah permukaan dan air tanah, dan daya dukung tanah. Terdapat 2 tipe pondasi yaitu pondasi dangkal yang didirikan di kedalaman tidak lebih dari $3 \mathrm{~m}$. Kemudian ada pondasi dalam yaitu pondasi yang didirikan di kedalaman tertentu untuk daya dukung besar dan dipasang di kedalaman lebih dari $3 \mathrm{~m}$. Pondasi dalam yang digunakan yaitu pondasi Tiang Pancang yang mempunyai daya dukung cukup untuk beban diatas nya pada lapisan paling dalam lebih dari $8 \mathrm{~m}$ dan proses pengerjaan langsung ditancapkan ke tanah.

\section{Konsep Utilitas}

Sumber air bersih pada lingkungan berasal dari PDAM, dan juga air hujan. Sistem distribusi air bersih yaitu up feed dan down feed. Sistem yang dibutuhkan yaitu mempertimbangkan distribusi air pompa yang tidak bekerja secara terus menerus sehingga lebih efisien dan awet megurangi kerusakan pompa namun juga air selalu tersedia setiap saat dan siap didistribusikan yaitu down feed. 
Menggunakan sistem down feed adalah sistem pipa distribusi air langsung dari tangki bawah dengan pompa kemudian dipompakan ke tangki air atas yang biasanya dipasang di atas atap atau lantai tertinggi bangunan selanjutnya air didistribusikan ke seluruh ruang bangunan yang membutuhkan air bersih.

Untuk air limbah yang berasal dari pelayanan medis memiliki distribusi berbeda yaitu harus filtrasi terlebih dahulu sebelum sebelum pembuangan ke riol kota. Filtrasi tersebut ialah melalui bak ekualisasi, bak pengendap awal, bak anaerob biofilter, aerob biofilter, pengendap akhir, dan diteruskan ke saluran riol kota dengan air yang tidak mencemari lingkungan saluran umum. Sedangkan untuk air limbah dari wastafel yang sudah diolah melalui perangkap lemak dan sabun dibuang ke riol kota, sebagian air hujan ditampung sedangkan air hujan yang tidak terpakai dibuang ke riol kota. Drainase terbagi menjadi dua dari air hujan untuk yang di tamping di penampungan air maupun yang langsung terbuang ke roil kota.

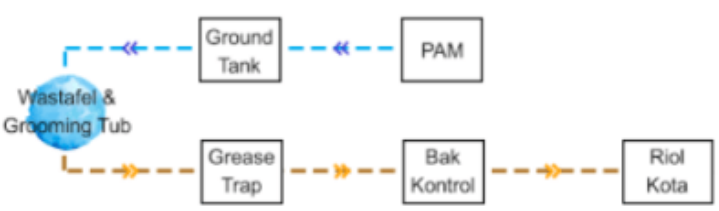

Gambar 6. Pengelolaan Air Limbah

Sumber: Penulis, 2020

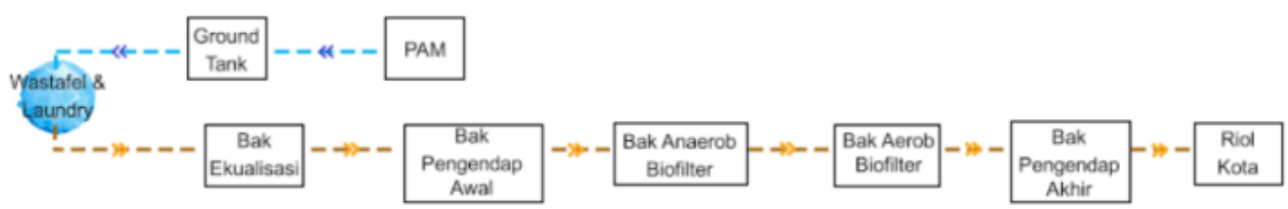

Gambar 7. Pengelolaan Air Limbah Medis

Sumber: Penulis, 2020

Pengelolaan kotoran padat diolah terlebih dahulu melalui septic tank sehingga tidak mencemari lingkungan. Pipa yang digunakan untuk mengalirkan kotoran dari lavatory ke septic tank memiliki diameter 6" dengan kemiringan minimal 6\% untuk pemasangan horizontal, dan vertikal untuk menggunakan shaft. Kotoran yang telah masuk ke septic tank setelahnya akan dialirkan ke sumur resapan.

Sumber energi listrik yang digunakan pada bangunan ini yaitu PLN serta Genset sebagai sumber energi listrik cadangan. Selain menggunakan sumber energi listrik dari PLN, kebutuhan listrik berupa Genset (Generator Set) sangat diperlukan. Apabila terjadi pemadaman arus listrik, maka otomatis genset akan bekerja 10 detik kemudian.

Bangunan pet care membutuhkan penyampaian informasi dalam satu waktu dan bersumber dari satu tempat namun memiliki speaker banyak dan bersamaan. Terdiri dari speaker coloumn, ceiling speaker, amplifier wireless, speaker indoor dan outdoor, amplifier automatic bell, dan microphone. Peralatan utama diletakkan di ruang kontrol. Penggunaan sistem suara ini dinilai lebih efisien karena dapat mengontrol sistem suara dibanyak tempat melalui satu sumber tempat. Selain itu bangunan ini juga membutuhkan pengawasan kamera CCTV dengan cakupan yang cukup jauh serta kualitas hasil rekaman jernih baik malam atau siang. CCTV yang digunakan yaitu Hikvision CCTV Dome Camera dengan jangkauan sudut rekaman 90 derajat. Radius jangkauan CCTV bisa merekam sejauh $20 \mathrm{~m}$.

Bangunan pet care membutuhkan sirkulasi udara yang baik karena terdapat hewan dan juga manusia yang ada di dalam bangunan. Dibutuhkan selalu udara segar di dalamnya dengan menghindari bau dalam ruang. Jika menggunakan penghawaan buatan (AC) kurang efektif karena ac 
mendinginkan udara dalam ruang tanpa mengeluarkan udara di dalam. Menggunakan exhaust dengan pertimbangan membuang udara dengan alasan salah satu contoh alat yang bekerja membuang udara adalah exhaust fan. Kipas ini berfungsi sebagai penyedot udara. Selain itu bisa membuang panas karena fungsi lain dari exhaust fan adalah untuk membuang panas yang ada pada ruangan dengan cara kerja exhaust fan ini akan efektif untuk mengendalikan suhu ruangan. Penggunaan exhaust fan dengan pertimbangan sirkulasi udara dimana pergantian udara akan sangat baik untuk mengatur kelembaban. Dengan sirkulasi udara yang baik, maka diharapkan ruang akan bisa digunakan dengan baik.

Berdasarkan prasarana yang harus dimiliki suatu Klinik sesuai dengan Peraturan Kementerian Kesehatan Nomor 9 tahun 2014 tentang Klinik yang menyebutkan salah satunya yaitu memiliki pencegahan dan penanggulangan kebakaran.

Tabel 1. Alat Proteksi Kebakaran
No Alat Proteksi Kebakaran
Fungsi

$1 \quad$ Smoke Detector

Pendeteksi adanya asap dalam ruang berupa alarm. Area deteksi dapat mencapai hingga $150 \mathrm{~m} 2$ dengan ketinggian plafon $4 \mathrm{~m}$ dari lantai.

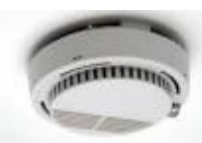

2 APAR

3 Sprinkler

4 Hydrant Bangunan

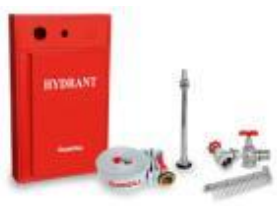

Bangunan Pet Care memiliki fungsi campuran sehingga tiap APAR dengan berat maksimum $2 \mathrm{~kg}$ dengan luas jangkauan luas $10 \mathrm{~m} 2$ dengan tiap penempatan setiap jarak maksimal $20 \mathrm{~m}$. Perletakan APAR biasanya gabung dengan kotak Hydrant.

5 Hydrant Halaman

Alat ini akan bekerja bila suhu udara di ruangan mencapai 60o c - 70o

c. Penutup kaca sprinkler akan pecah dan mengeluarkan air. Jarak antara dua sprinkler biasanya $4 \mathrm{~m}$ didalam ruangan.

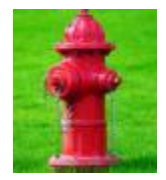

Hydrant bangunan ditempatkan maksimal 25 - $35 \mathrm{~m}$ dan mudah dijangkau. Selang hydrant berukuran diameter 1,5' - 2', harus terbuat dari bahan yang tahan panas, dengan panjang 20 - $30 \mathrm{~m}$. Hydrant dipasang tiap $800 \mathrm{~m} 2$ / unit. 
Perlindungan bangunan bagian luar dari petir membutuhkan penangkal petir yang baik dan menggunakan penangkal petir Thomas yang merupakan penangkal petir eksternal yang berfungsi sebagai konduktor baik sehingga dapat menyalurkan arus petir ke grounding. Penggunaan penangkal petir Thomas yaitu pada lapangan terbuka, pertambangan, Gedung perkantoran, rumah sakit, stadion, dll. Penangkal petir Thomas yang digunakan yaitu tipe Viking dapat menangkal petir sejauh radius 120 m dengan tipe V6 seberat 7 kg bermaterial Stainless Steel berwarna silver. Penangkal petir yang digunakan yaitu penangkal petir Thomas dengan pertimbangan arus listrik dari petir yang menyambar akan disalurkan ke bawah tanah untuk dinetralkan melalui kabel grounding, dengan radius $60 \mathrm{~m}-150 \mathrm{~m}$.

Persampahan pada bangunan pet care juga perlu dipertimbangkan pengelolaan nya. Menurut Peraturan Menteri Kesehatan Nomor 9 tahun 2014 tentang Klinik berdasarkan potensi bahaya yang terkandung di dalamnya, timbulan sampah untuk fungsi pelayanan medis berupa klinik hewan dan perawatan hewan dinyatakan dalam satuan $\mathrm{kg} /$ hari dan sampah harus dibuang setiap hari. Kemudian terdapat pemisahan untuk sampah medis dan juga sampah umum yang terbagi menjadi tiga yaitu sampah organik, non organik, dan b3 (bahan berbahaya dan beracun) dengan perkiraan jumlah sampah untuk keperluan penampungan dan pembakaran sampah untuk fungsi pengelola dan komersil mengacu pada fungsi bangunan perkantoran yaitu $4.5 \mathrm{~kg} / \mathrm{m} 2$.

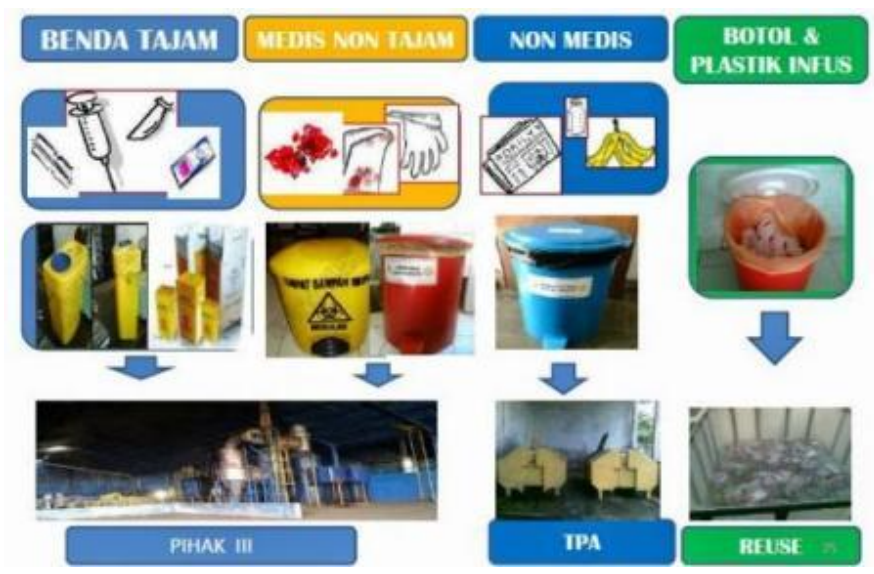

Gambar 8. Klasifikasi Limbah Medis

Sumber: PERMENKES, 2014

\section{Konsep Fisika Bangunan}

Pertimbangan terhadap bangunan dalam hal fisika bangunan dapat diaplikasikan berupa roster, sun shading, jenis atap, maupun penghawaan alami berupa jendela dan penghawaan buatan berupa AC. Sun shading digunakan pada luar bangunan yang berguna estetik dan juga untuk mengurangi intensitas cahaya yang masuk ke ruangan dengan cara menghalangi sinar melalui sekat luar bangunan sehingga tidak menyebabkan silau atau pun mengurangi panas dalam bangunan. Digunakan pada area yang banyak terkena cahaya matahari sore. Material yang digunakan yaitu Aluminium karena tidak mudah karat, kuat namun tetap ringan. Kemudian menggunakan jenis atap Perisai mengkuti ruang di dalam nya. Atap perisai cocok menyesuaikan kondisi iklim baik hujan maupun menyerap panas dengan baik. Selain itu terdapat atap setengah pelana di bagian depan bangunan untuk menambah estetika. Selanjutnya jendela tanpa roster atau sun shading terdapat di tiap masing bangunan. Jendela ini direncanakan ada yang jendela mati dan tidak serta berukuran besar dan kecil untuk memasukkan cahaya matahari pagi khususnya dan sebagai cahaya tambahan dalam ruang selain pemakaian lampu. Penghawaan lebih banyak menggunakan penghawaan alami dengan bantuan exhaust fan. 


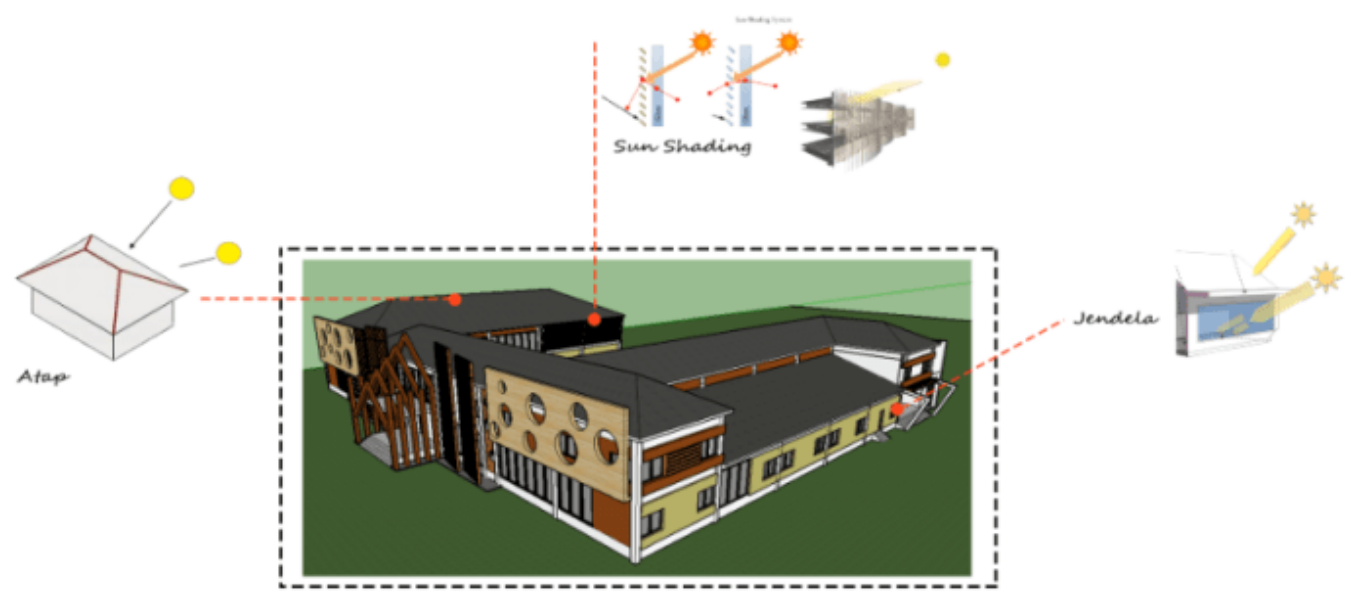

Gambar 9. Fisika Bangunan

Sumber: Penulis, 2020

\section{E. Hasil Perancangan}

Bangunan Pet Care Kalimantan Barat di Kota Pontianak berada diatas lahan dengan luas 7.000 $\mathrm{m} 2$. Ruang luar pada siteplan yaitu area hijau, parkir, dan sirkulasi. Area hijau tersebar di sekitar site dimulai dari entrance masuk hingga keluar. Area parkir juga tersebar di beberapa titik dengan 2 jenis kendaraan yaitu mobil dan motor. Parkir khusus pengelola terletak terpisah dengan umum. Untuk entrance utama masuk melalui Jl. Purnama sedangkan entrance keluar utama yaitu Family Residence. Bangunan Pet Care Kalimantan Barat di Kota Pontianak terdiri dari satu massa bangunan dengan dua lantai. Pembagian ruang yang disusun menyesuaikan penataan ruang dalam pada analisis sebelumnya. Entrance bangunan memiliki dua akses yaitu entrance untuk pengunjung umum dan entrance pengelola yang terpisah. Tiap lantai bangunan terdiri dari tiga jenis fungsi berbeda yaitu pelayanan medis, perawatan hewan, dan pengelola. Terdapat area sirkulasi berupa teras di tengah bangunan dan taman untuk melihat view ke arah Agility Training.
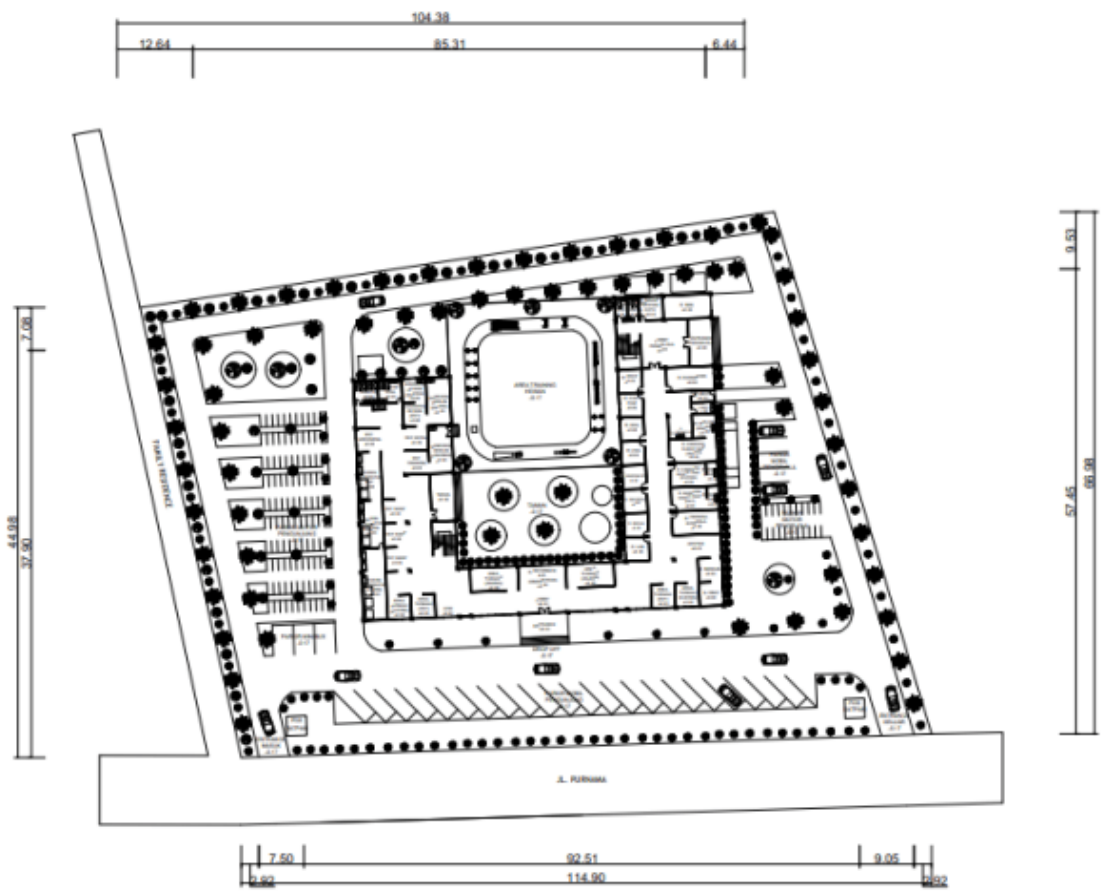

Gambar 10. Site plan Bangunan Pet Care

Sumber: Penulis, 2020 
Tampak bangunan merupakan gambaran muka bangunan dari empat sisi yaitu itu depan, belakang, kanan, dan kiri. Tampak juga menunjukkan fasad bangunan baik bentuk, warna, letak, dan perbandingan bangunan.
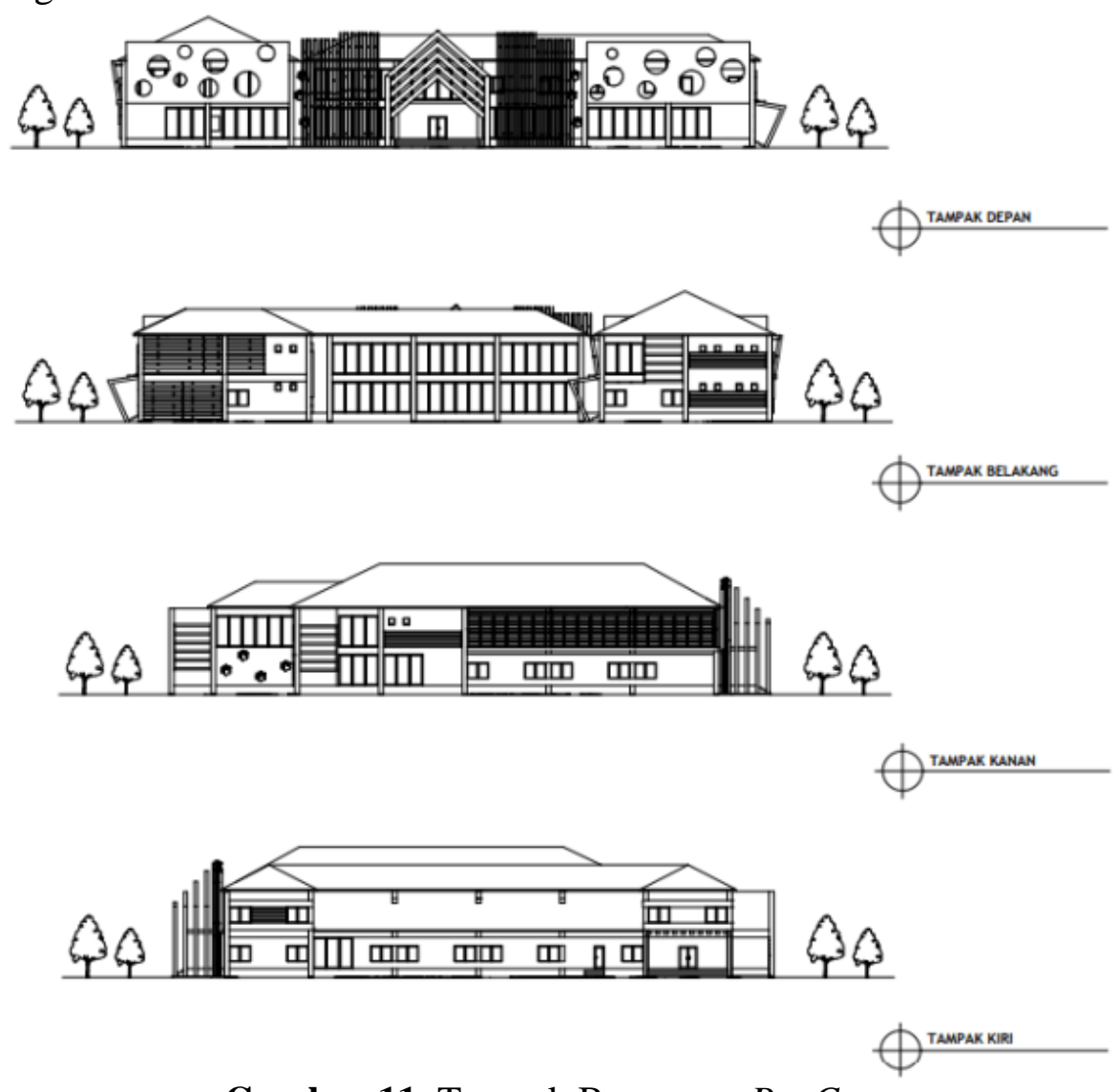

Gambar 11. Tampak Bangunan Pet Care

Sumber: Penulis, 2020

Suasana eksterior bangunan Pet Care Kalimantan Barat di Kota Pontianak terdiri dari satu massa bangunan dengan orientasi bangunan menghadap ke Jl. Purnama dengan orientasi akses entrance masuk bangunan yang berada di samping yaitu menghadap ke Family Residence. Bangunan ini didominasi warna putih dan warna coklat.

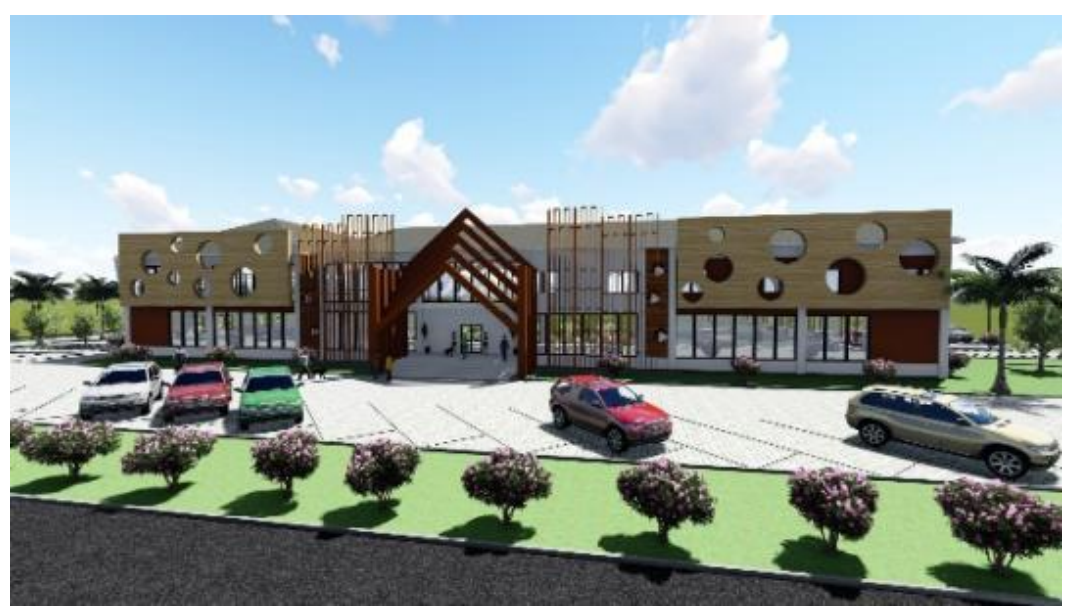

Gambar 12. Suasana Sekitar Entrance Pet Care

Sumber: Penulis, 2020 
Kemudian eksterior yang menggambarkan Agility Training Pet Care yang menjadi fasilitas utama dan kelebihan di Pet Care ini. Berada di belakang bangunan dengan luas $900 \mathrm{~m} 2$ dengan mengikuti standar Federation Cynologique Internationale untuk peralatan maupun luasan khusus Agility Training.

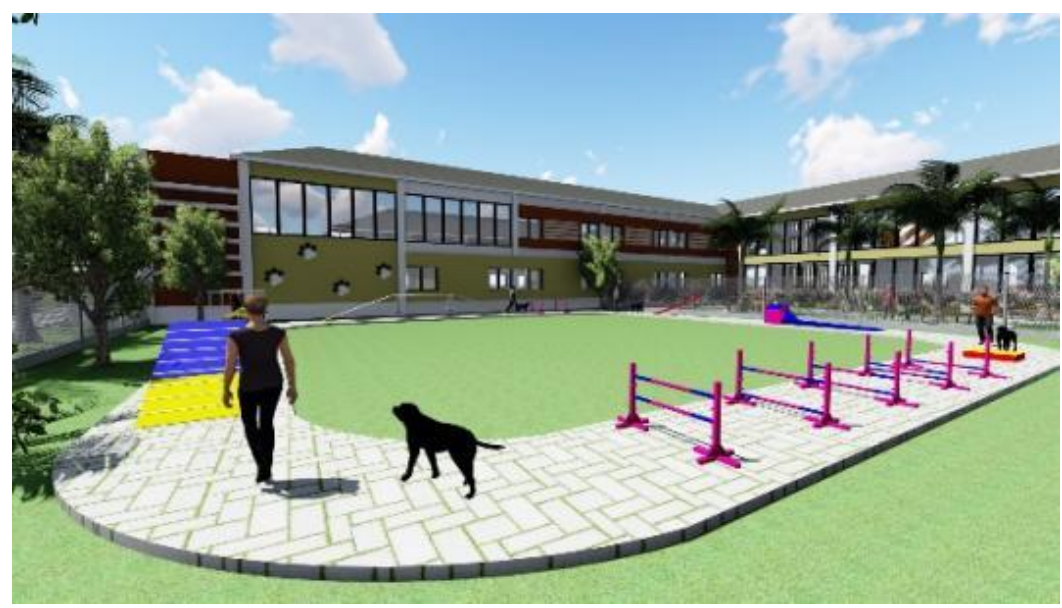

Gambar 13. Suasana Agility Training Pet Care

Sumber: Penulis, 2020

Suasana interior memperlihatkan lobby Pet Care yang berada di depan bangunan lantai satu dengan akses langsung ke pelayanan medis berupa apotek, area tunggu, dan ruang informasi. Warna yang mendominasi yaitu putih dengan warna coklat.

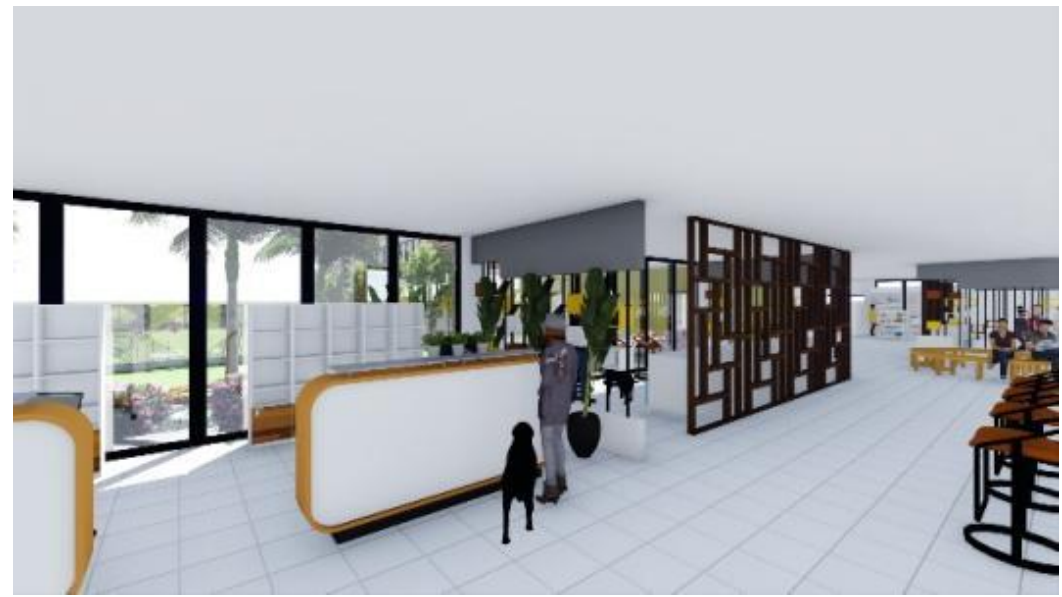

Gambar 14. Suasana Lobby Pet Care

Sumber: Penulis, 2020

Kemudian ruang lain memperlihatkan suasana ruang periksa \& konsul yang berada di lantai satu. Memiliki warna dominasi putih, dan kuning, dengan aksen wood pada lemari. Terdapat meja dan kursi untuk konsultasi, rak buku, serta meja periksa. 


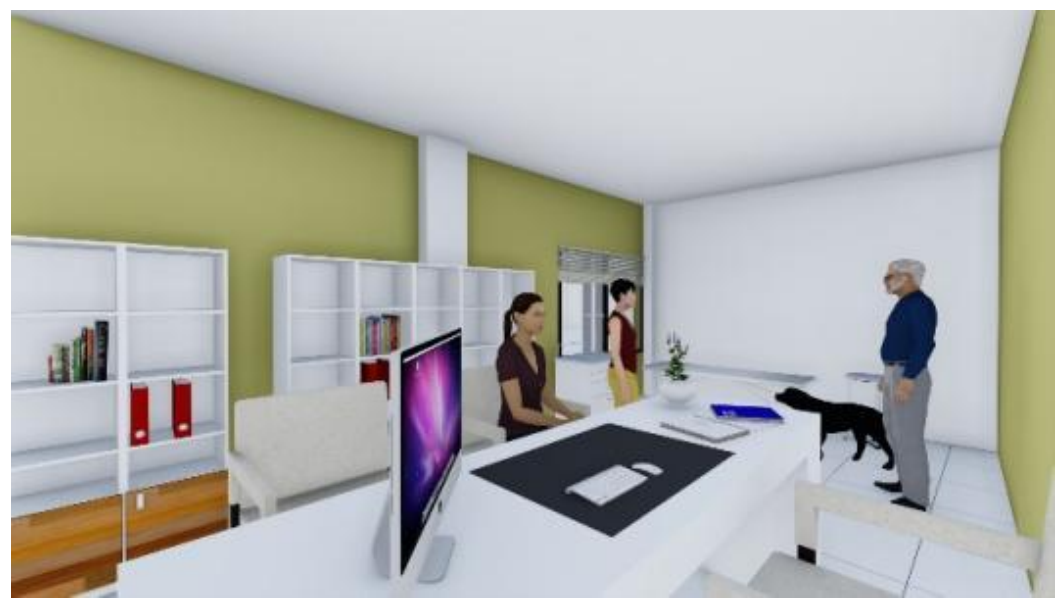

Gambar 15. Suasana Ruang Periksa \& Konsul

Sumber: Penulis, 2020

\section{Kesimpulan}

Pet care ini didasari oleh data penyakit dari Capaian Kinerja Terkendalinya Penyakit Hewan Menular Strategis yaitu Pengendalian penyakit Hewan Menular Strategis di Kalimantan Barat pada tahun 2018 dapat digambarkan dengan lima jenis penyakit hewan yang banyak ditemukan di Provinsi Kalimantan Barat. Selain itu juga Di Kota Pontianak terdapat banyak pet shop ataupun klinik dengan dokter hewan sebagai penanggung jawab nya. Letak pet shop dan klinik tersebut tersebar dan juga ada yang bergabung atau bersebelahan dengan ruko atau area komersil umum lain. Untuk kegiatan atau event juga biasa diadakan di tempat umum dan bebas tidak pada satu tempat tetap. Maka dari itu Pet Care ini yang merupakan tempat pelayanan Kesehatan dan perawatan hewan memiliki dengan fasilitas penunjang yang sesuai dengan pet care itu sendiri atau Perawatan Hewan, namun juga yang berkaitan dengan perawatan hewan tersebut berupa pet shop, pet grooming, pet hotel, pet show / expo, pet training, serta pelayanan pendukung untuk pengunjung umum berupa café and culinary dan retail shop yang menjadi pelayanan lebih pada perancangan pet care di Kota Pontianak.

\section{Ucapan Terima Kasih}

Ucapan syukur penulis kepada Allah SWT dan terima kasih dipersembahkan kepada kedua orangtua serta keluarga yang tidak ada hentinya dalam memberikan dukungan dan semangat. Penulis juga mengucapkan terima kasih kepada dosen yang telah memberikan bimbingan dalam menyelesaikan laporan. Selain itu ucapan terima kasih diberikan kepada teman - teman dan seluruh pihak yang telah memberi dukungan dan kontribusi dalam penyelesaian tugas akhir ini.

\section{Daftar Acuan}

Amie, A. (2007). Semarang Pet Centre. Semarang, Indonesia: Fakultas Teknik. Universitas Negeri Semarang

Dinas Pangan, Peternakan, dan Kesehatan Hewan Provinsi Kalimantan Barat. (2019, September 30 ). Capaian Kinerja Terkendalinya Penyakit Hewan Menular Strategis. Retrieved from https://www.dppkh.kalbarprov.go.id

Nuraini, C. (2010). Metode Perancangan Arsitektur. Bandung: Karya Putra Darwati

Federation Cynologique Internationale. (2018). Agility Regulations of the Federation Cynologique Internationale. Thuin, Belgia: Federation Cynologique Internationale

Kementerian Kesehatan Republik Indonesia. (2014). Peraturan Menteri Kesehatan Nomor 9 tahun 2014 tentang Klinik. Jakarta: Kementerian Kesehatan Republik Indonesia

Sekretariat Negara Republik Indonesia. (2009). Undang - Undang Nomor 18 Tahun 2009 tentang Peternakan dan Kesehatan Hewan. Jakarta: Sekretariat Negara Republik Indonesia

Kementerian Pertanian Republik Indonesia. (2010). Peraturan Menteri Pertanian tahun 2010 tentang Pedoman Pelayanan Jasa Medik Veteriner. Jakarta: Kementerian Pertanian Republik Indonesia

Sealey, L. (1974). Our World Encyclopedia. London: Macmillan 